\title{
Review
}

\section{A systematic review of the recent ecological literature on cushion plants: champions of plant facilitation}

\author{
Anya M. Reid, Laurent J. Lamarque and Christopher J. Lortie
}

Reid, A. M., Lamarque, L. J. and Lortie, C. J. 2010. A systematic review of the recent ecological literature on cushion plants: champions of plant facilitation. - Web Ecol. 10: 44-49.

\begin{abstract}
Cushion-forming plant species are found in alpine and polar environments around the world. They modify the microclimate, thereby facilitating other plant species. Similar to the effectiveness of shrubs as a means to study facilitation in arid and semi-arid environments, we explore the potential for cushion plant species to expand the generality of research on this contemporary ecological interaction. A systematic review was conducted to determine the number of publications and citation frequency on relevant ecological topics whilst using shrub literature as a baseline to assess relative importance of cushions as a focal point for future ecological research. Although there are forty times more shrub articles, mean citations per paper is comparable between cushion and shrub literature. Furthermore, the scope of ecological research topics studied using cushions is broad including facilitation, competition, environmental gradients, life history, genetics, reproduction, community, ecosystem and evolution. The preliminary ecological evidence to date also strongly suggests that cushion plants can be keystone species in their ecosystems. Hence, ecological research on net interactions including facilitation and patterns of diversity can be successfully examined using cushion plants, and this is particularly timely given expectations associated with a changing climate in these regions.
\end{abstract}

A. M. Reid (anyareid@yorku.ca), L. J. Lamarque and C. J. Lortie, Dept of Biology, York Univ., Toronto, Ontario, Canada, M3J 1P3.

\section{The ecology of cushion plants}

It is widely recognized that plant interactions are important factors when considering community ecology (Brooker and Callaghan 1998, Kikvidze et al. 2005, Brooker et al. 2008, Arredondo-Núñez et al. 2009). More specifically, the structure and function of plant communities is now recognized as being influenced by positive interactions (Callaway 1995, 2007, Mulder et al. 2004, ArredondoNúñez et al. 2009, Butterfield 2009), especially in those with harsh abiotic conditions (Bertness and Callaway 1994, Callaway and Walker 1997, Arroyo et al. 2003, Cavieres et al. 2006). Although competition studies have dominated the plant interaction literature, facilitation studies are now being cited by the scientific community at approximately the equivalent rate (Lortie and Callaway 2009). Of the 754 publications on 'facilitation' and 'plants' listed by the ISI Web of Science database in Oct 2009, roughly onethird also contain the topic word 'shrub' and one-quarter with the topic words 'arid' or 'semi-arid' (Flores and Jurado 2003). Cushion-forming plant species can be used to advance understanding and assess patterns of positive plant interactions in cold alpine and polar regions globally.

Cushion-forming plant species (hereafter termed 'cushions' sensu Arredondo-Núnez et al. 2009) are excellent candidates to investigate positive interactions and their 
cumulative effects on community structure. There are 338 recorded cushion species in 78 genera and 34 plant families that are distributed globally in harsh alpine and polar regions (Hauri and Schröter 1914, Arredondo-Núnez et al. 2009). This distinct vegetative form of hardy vascular plant is thought to be one of the best adapted growth forms to alpine and polar environments (Billings and Mooney 1968, Pysek and Liska 1991, Chapin and Korner 1995, Korner 2003). Their domed shape enables them to moderate temperature (Salisbury and Spomer 1964, Cavieres et al. 1998, Molina-Montenegro et al. 2000, Arroyo et al. 2003, Nyakatya and McGeoch 2008), store moisture (Pysek and Liska 1991, Cavieres et al. 1998, Nunez et al. 1999), increase soil quantity and nutrients (Nunez et al. 1999, Cavieres et al. 2008), and protect from abrasive wind (Hager and Faggi 1990, Cavieres et al. 2006). By improving growth conditions in severe habitats, cushions are excellent facilitators (Moen 1993, Choler et al. 2001, Cavieres et al. 2002, 2008, Badano and Cavieres 2006, Badano et al. 2006, Antonsson et al. 2009, Sklenar 2009) and may potentially stabilize species diversity (Badano et al. 2006). This enables cushions to aid in species succession at multiple spatial scales (Smith 1987, Gibson and Kirkpatrick 1992, Mark and Bastow 2005, Badano and Cavieres 2006) and act as a keystone species contributing to the structure and function of the ecosystem (le Roux and McGeoch 2004, le Roux et al. 2005, Badano and Marquet 2008, Mortimer et al. 2008, Nyakatya and McGeoch 2008, Phiri et al. 2009). Furthermore, the role of cushions as facilitators in these harsh ecosystems is not redundant as more erect plants cannot modify the abiotic conditions associated with positive effects on germination and survival (Moen 1993). Hence, while shrubs may be an ideal set of species to study net interactions in arid and semi-arid systems, cushions could be the analog for experimentation in the alpine and polar systems where accumulating evidence shows that climate change effects will be more intense (Pauli et al. 1996, Guisan and Theurillat 2000, Sala et al. 2000, Walther et al. 2002). Ultimately, cushion-forming plant species could be used to examine the effects of climate change at a neighbourhood level with the goal of extrapolating to changing communities.

\section{Systematic review}

In order to determine the potential scientific capacity of cushions to expand research on net interactions, we conducted a systematic review using ISI Web of Science in Sep 2009. An initial search for publications containing the words 'cushion plant' resulted in 79 articles, of which 13 were not used due to unrelated material (11) or language (2). The 66 remaining publications are all relatively recent (1987-2009) and in English journals. This body of literature was grouped into nine topics (facilitation, competition, environmental gradient, life history, genetic, reproduction, community, ecosystem and evolution). From these groups of literature publication number, citation rates and selfcitation biases were collected (Fig. 1). These nine topics were also used to group publications on shrubs in order to contrast publication and citation rates for these two growth forms. By comparing two vegetative forms in nine topics the sample size for statistical analysis is 18 . General linear models were used to determine whether number of publications or citations per publication differed between shrubs and cushion plants. The following attributes of the literature associated with cushions were addressed: (1) a survey of the number of cushion species studied, (2) an assessment of the geographical range of cushion research, (3) the scope of ecological topics studied, and finally, (4) the frequency of citations to these publications relative to shrub studies. Taken together, these attributes provide a concrete means to review and identify the current and potential merits of studying cushions.

\section{The ecological significance of cushions plants: heavy or light weight players?}

The increasing number of publications on this set of species by many authors in a diverse range of journals indicates that cushions are an increasingly important plant form for studying ecological interactions. A total of 49 distinct cushion plant species have been studied in addition to three genera (Abrotanella, Distichia and Oxychole) being collectively studied. Silene acaulis is the most frequently studied species with 12 publications, followed by Azorella monantha with 7 publications, and Laretia acaulis and Azorella selago each with 6 publications. The majority of these 49 cushion plant species $(71.4 \%)$ have, however, only been studied once. Furthermore, the 49 cushion spe-

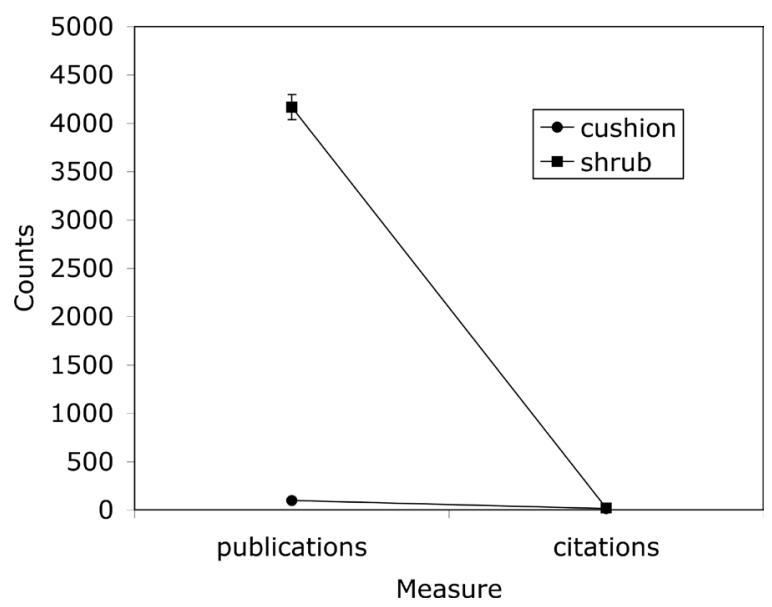

Figure 1. Number of publications and citations from an ISI Web of Science search for 'cushion plant' and 'shrub'. Error bars denote $\pm 1 \mathrm{SE}$. 
cies reported in this review are only a small fraction, $6.9 \%$, of the total number of cushion species (334) currently identified by Hauri and Schröter (1914). Thus, from this review $93 \%$ of cushion species have not been studied. The species that have been studied however are distributed globally with the highest number of publications originating in Chile followed by the USA (Fig. 2).

Ecological interactions between cushions and other organisms have been a dominant focus of this literature (62 of 66 publications) including research on facilitation (15), competition (11), communities (19), and ecosystems (17). For instance, Azorella madreporica, a Chilean cushion species, was found to display both positive and negative associations with plant species depending on the plants location outside or inside the cushion vegetation (Fajardo et al. 2008). Plant interactions associated with cushions and environmental gradients supports the stress gradient hypothesis (Bertness and Callaway 1994) showing that the frequency of facilitation increases with environmental severity (Smith et al. 1995, Badano et al. 2007, Cavieres and Badano 2009). Studies on the biology of cushions have also generated a substantial body of literature (32 publications) including research on life history (7), genetics (9), reproduction (10), and evolution (6). These studies have found cushions to be stress tolerant, slow growing and long lived plants (McCarthy 1992) with sexual repro- duction (requiring active pollination) being the main contributor to the next generation (Arroyo et al. 1982, Morris and Doak 1998, Zoller et al. 2002).

As these organisms have been estimated to be up to 3000 years old (Ralph 1978), the genetic structure can be influenced by historic distributions and colonization events (Heads 1999, Geng et al. 2009). Conversely, however, high genetic variation has been found within populations (Abbott et al. 1995, Gehring and Delph 1999, Gugerli et al. 1999, Pluess and Stocklin 2004), suggesting long distance pollen transport by insects (Gugerli et al. 1999). The current literature on cushions provides an introduction to the species and how they might be interacting but is still far from comprehensive.

There are significantly more publications on shrubs compared to cushions on these broad ecological topics (GLM, chi-square $=7.1, \mathrm{p}=0.008, \mathrm{n}=18)$ including 250 on facilitation, 746 on competition, 130 on environmental gradient, 206 on life history, 149 on genetics, 259 on reproduction, 1254 on community, 853 on ecosystem and 319 on evolution. However, there was no significant difference between the citation rate per publication between cushion and shrub literature (GLM, chi-square $=1.8, \mathrm{p}=$ $0.176, \mathrm{n}=18$ ) in spite of the fact that there was an order magnitude less cushion publications (98 vs 4166 from an ISI Web of Science search for the topics 'cushion plants'

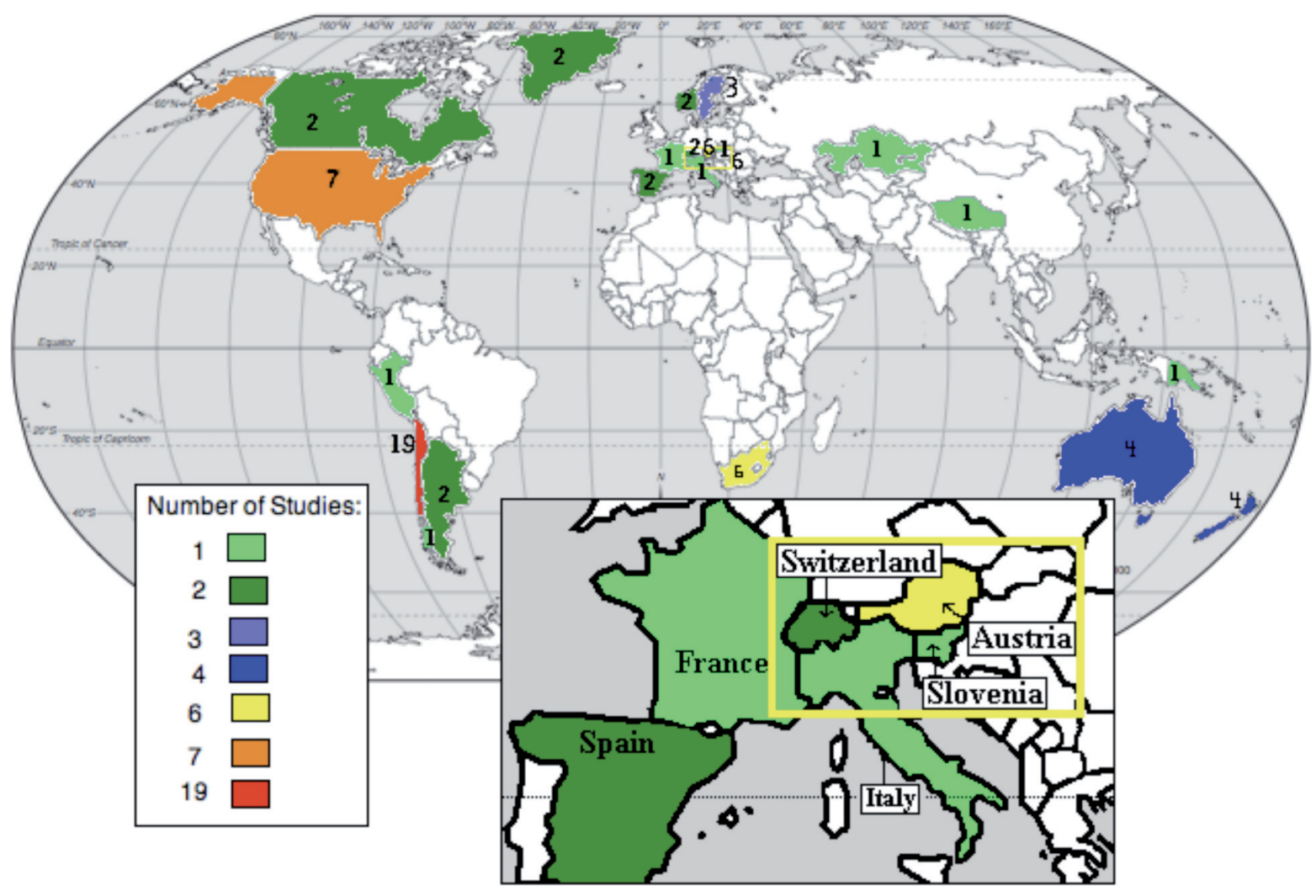

Figure 2. World map illustrating the geographic distribution of cushion plant research from the literature in this review. 


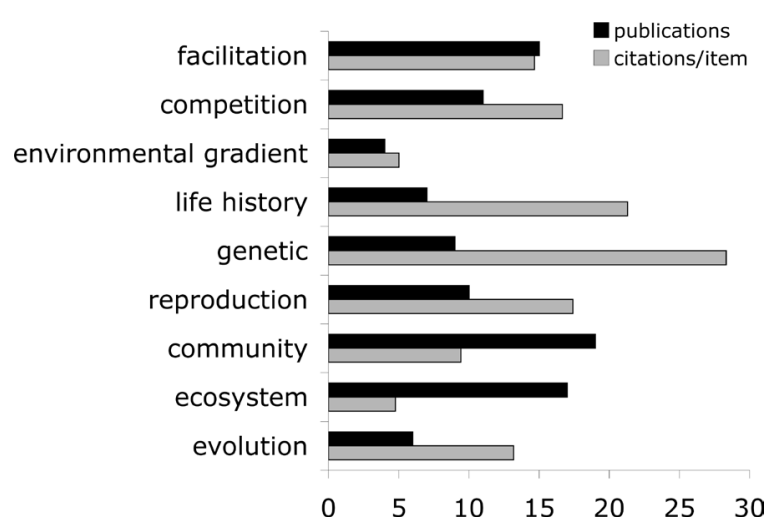

Figure 3. Number of publications and average number of citations per publication from an ISI Web of Science search for 'cushion plant' and 'facilitation', 'competition', 'environmental gradient', 'life history', 'genetic', 'reproduction', 'community', 'ecosystem' and 'evolution', respectively.

and 'shrubs', respectively; Fig. 3). This strongly suggests that the cushion literature is well-cited and highly visible to ecologists. In other words, studies using cushion plants are as useful as those on shrubs, but also expand our capacity to examine these topics because cushions are found in different ecosystems and biomes. Importantly, cushions may be keystone species because they are generally found at low densities (i.e. mean density of 0.55 cushions $\mathrm{m}^{-2}$ in the sub-Antarctic Marion Island, Nyakatya and McGeoch 2008, Phiri et al. 2009) and have large impacts on local species diversity (percentage of positive plant associations with cushions depends largely on environmental harshness with a mean of $47 \%$ in harsh environments and $22 \%$ in less harsh environments from Arroyo et al. 2003 and Cavieres et al. 2006). Cushions influence the plant community over a long temporal scale as they have been shown to take part in successional processes (Smith 1987, Gibson and Kirkpatrick 1992, Mark and Bastow 2005, Badano and Cavieres 2006). Cushions are also nurse-plant species as they have been shown to facilitate other plant species (Núñez et al. 1999, Cavieres et al. 2005, 2006, AcunaRodriguez et al. 2006, Antonsson et al. 2009). Research on cushion individuals and cushion community interactions is critical given that climate change and biological invasions are dramatically increasing in the alpine and polar regions (Sala et al. 2000). Hence, understanding cushion dynamics and their effects may be a crucial element in understanding larger ecological phenomenon, and cushions may become the next champions of facilitation and stress research in plant ecology but in systems that are warming and changing rapidly.

Acknowledgements - Natural Sciences and Engineering Research Council of Canada's Discovery Grant to CJL and Ontario Graduate Scholarship in Science and Technology Grant to AMR funded this research.

\section{References}

Abbott, R. J. et al. 1995. Molecular diversity and derivations of populations of Silene acaulis and Saxifraga oppositifolia from the high Arctic and more southerly latitudes. - Mol. Ecol. 4: 199-207.

Acuna-Rodriguez, I. S. et al. 2006. Nurse effect in seedling establishment: facilitation and tolerance to damage in the Andes of central Chile. - Rev. Chilena Hist. Nat. 79: 329-336.

Antonsson, H. et al. 2009. Nurse plant effect of the cushion plant Silene acaulis (L.) Jacq. in an alpine environment in the subarctic Scandes, Sweden. - Plant Ecol. Div. 2: 17-25.

Arredondo-Núñez, A. et al. 2009. How beneficial are nurse plants? A meta-analysis of the effects of cushion plants on high-Andean plant communities. - Comm. Ecol. 10: 1-6.

Arroyo, M. T. K. et al. 1982. Community studies in pollination ecology in the high temperate Andes of central Chile. I. Pollination mechanisms and altitudinal variation. - Am. J. Bot. 61: 82-97.

Arroyo, M. T. K. et al. 2003. Positive associations between the cushion plant Azorella monantha (Apiaceae) and alpine plant species in the Chilean Patagonian Andes. - Plant Ecol. 169: 121-129.

Badano, E. I. and Cavieres, L. A. 2006. Ecosystem engineering across ecosystems: do engineer species sharing common features have generalized or idiosyncratic effects on species diversity? - J. Biogeogr. 33: 304-313.

Badano, E. I. and Marquet, P. A. 2008. Ecosystem engineering affects ecosystem functioning in high-Andean landscapes. Oecologia 155: 821-829.

Badano, E. I. et al. 2006. Assessing impacts of ecosystem engineers on community organization: a general approach illustrated by effects of a high-Andean cushion plant. - Oikos 115: 369-385.

Badano, E. I. et al. 2007. Ecosystem engineering facilitates invasions by exotic plants in high-Andean ecosystems. - J. Ecol. 95: 682-688.

Bertness, M. and Callaway, R. M. 1994. Positive interactions in communities. - Trends Ecol. Evol. 9: 191-193.

Billings, W. D. and Mooney, H. A. 1968. The ecology of arctic and alpine plants. - Biol. Rev. 43: 481-529.

Brooker, R. W. and Callaghan, T. V. 1998. The balance between positive and negative plant interactions and its relationship to environmental gradients: a model. - Oikos 81: 196-207.

Brooker, R. W. et al. 2008. Facilitation in plant communities: the past, the present, and the future. - J. Ecol. 96: 8-34.

Butterfield, B. J. 2009. Effects of facilitation on community stability and dynamics: synthesis and future directions. - J. Ecol. 97: 1192-1201.

Callaway, R. M. 1995. Positive interactions among plants. - Bot. Rev. 61: 306-249.

Callaway, R. M. 2007. Positive interactions and interdependence in plant communities. - Springer.

Callaway, R. M. and Walker, L. R. 1997. Competition and facilitation: a synthetic approach to interactions in plant communities. - Ecology 78: 1958-1965.

Cavieres, L. A. and Badano, E. I. 2009. Do facilitative interactions increase species richness at the entire community level? - J. Ecol. 97: 1181-1191. 
Cavieres, L. A. et al. 1998. Efecto nodriza del cojin Laretia acaulis (Umbelliferae) en la zona alto-andina de Chile central. - Rev. Chilena Hist. Nat. 71: 337-347.

Cavieres, L. A. et al. 2002. Nurse effect of Bolax gummifera cushion plants in the alpine vegetation of the Chilean Patagonian Andes. - J. Veg. Sci. 13: 547-554.

Cavieres, L. A. et al. 2005. Nurse effect of the native cushion plant Azorella monantha on the invasive non-native Taraxacum officinale in the high-Andes of central Chile. - Persp. Plant Ecol. Evol. Syst. 7: 217-226.

Cavieres, L. A. et al. 2006. Positive interactions between alpine plant species and the nurse cushion plant Laretia acaulis do not increase with elevation in the Andes of central Chile. New Phytol. 169: 59-69.

Cavieres, L. A. et al. 2008. Facilitation of the non-native Taraxacum officinale by native nurse cushion species in the high Andes of central Chile: are there differences between nurses? - Funct. Ecol. 22: 148-156.

Chapin, F. S. and Korner, C. 1995. Arctic and alpine biodiversity ecological studies. - Springer.

Choler, P. et al. 2001. Facilitation and competition on gradients in alpine plant communities. - Ecology 82: 3295-3308.

Fajardo, A. et al. 2008. Spatial patterns in cushion-dominated plant communities of the high Andes of central Chile: how frequent are positive associations? - J. Veg. Sci. 19: 87-96.

Flores, J. and Jurado, E. 2003. Are nurse-protégé interactions more common among plants from arid environments? - J. Veg. Sci. 14: 911-916.

Gehring, J. L. and Delph, L. F. 1999. Fine-scale genetic structure and clinal variation in Silene acaulis despite high gene flow. Heredity 82: 628-637.

Geng, Y. et al. 2009. Fine- and landscape-scale spatial genetic structure of cushion rockjasmine, Androsace tapete (Primulaceae), across southern Qinghai-Tibetan Plateau. - Genetica 135: 419-427.

Gibson, N. and Kirkpatrick, J. B. 1992. Dynamics of a Tasmanian cushion heath community. - J. Veg. Sci. 3: 647-654.

Gugerli, F. et al. 1999. Promiscuity in populations of the cushion plant Saxifraga oppositifolia in the Swiss Alps as inferred from random amplified polymorphic DNA (RAPD). - Mol. Ecol. 8: 453-461.

Guisan, A. and Theurillat, J.-P. 2000. Assessing alpine plant vulnerability to climate change: a modeling perspective. - Integr. Assess. 1: 307-320.

Hager, J. and Faggi, A. M. 1990. Observaciones sobre distribucion y microclima de cojines enanos de la isla de Creta y del noroeste de la Patagonia. - Parodiana 6: 109-127.

Hauri, H. and Schröter, C. 1914. Versuch einer Übersicht der siphonogamen Polsterpflanzen. - Bot. Jahrb. Syst. Pflanzengesch. Pflanzengeogr. 50: 618-656.

Heads, M. 1999. Vicariance biogeography and terrane tectonics in the South Pacific: analysis of the genus Abrotanella (Compositae). - Biol. J. Linn. Soc. 67: 391-432.

Kikvidze, Z. et al. 2005. Linking patterns and processes in alpine plant communities: a global study. - Ecology 86: 1395-1400.

Korner, C. 2003. Alpine plant life. - Springer.

le Roux, P. C. and McGeoch, M. A. 2004. The use of size as an estimator of age in the subantarctic cushion plant, Azorella selago (Apiaceae). - Arct. Antarct. Alp. Res. 36: 509-517. le Roux, P. C. et al. 2005. Effects of a short-term climate change experiment on a sub-Antarctic keystone plant species. Glob. Change Biol. 11: 1628-1639.

Lortie, C. J. and Callaway, R. M. 2009. David and Goliath: comparative use of facilitation and competition studies in the plant ecology literature. - Web Ecol. 9: 54-57.

Mark, A. F. and Bastow, W. J. 2005. Tempo and mode of vegetation dynamics over 50 years in a New Zealand alpine cushion / tussock community. - J. Veg. Sci. 16: 227-236.

McCarthy, D. P. 1992. Dating with cushion plants: establishment of a Silene acaulis growth curve in the Canadian Rockies. - Arct. Alp. Res. 24: 50-55.

Moen, J. 1993. Positive versus negative interactions in a high alpine block field: germination of Oxyria digyna seeds in a Ranunculus glacialis community. - Arct. Alp. Res. 25: 201-206.

Molina-Montenegro, M. A. et al. 2000. Asociacion de especies al cojin Azorella trifurcata (Gaertn.) Hook. (Apiaceae) en la zona andina de Chile central (37S). - Gayana Bot. 57: $161-168$.

Morris, W. F. and Doak, D. F. 1998. Life history of the long-lived gynodioecious cushion plant Silene acaulis (Caryophyllaceae), inferred from size-based population projection matrices. - Am. J. Bot. 85: 784-793.

Mortimer, E. et al. 2008. Growth form and population genetic structure of Azorella selago on sub-Antarctic Marion Island. - Antarct. Sci. 20: 381-390.

Mulder, C. P. H. et al. 2004. Species evenness and productivity in experimental plant communities. - Oikos 107: 50-63.

Núnez, C. I. et al. 1999. Species associations and nurse plant effects in patches of high-Andean vegetation. - J. Veg. Sci. 10: 357-364.

Nyakatya, M. J. and McGeoch, M. A. 2008. Temperature variation across Marion Island associated with a keystone plant species (Azorella selago Hook. (Apiaceae). - Polar Biol. 31: 139-151.

Pauli, H. et al. 1996. Effects of climate change on mountain ecosystems - upward shifting of alpine plants. - World Resour. Rev. 8: 382-390.

Phiri, E. E. et al. 2009. Spatial variation in structural damage to a keystone plant species in the sub-Antarctic: interactions between Azorella selago and invasive house mice. - Antarct. Sci. 21: 189-196.

Pluess, A. R. and Stocklin, J. 2004. Population genetic diversity of clonal plant Geum reptans (Rosaceae) in the Swiss Alps. Am. J. Bot. 91: 2013-2021.

Pysek, P. and Liska, J. 1991. Colonization of Sibbaldia tetrandra cushions on alpine scree in the Pamiro-Alai Mountains, central Asia. - Arct. Alp. Res. 23: 263-272.

Ralph, C. P. 1978. Observations on Azorella compacta (Umbelliferae), a tropical Andean cushion plant. - Biotropica 10: $62-67$.

Sala, O. E. et al. 2000. Global biodiversity scenarios for the year 2100. - Science 287: 1770-1774.

Salisbury, F. B. and Spomer, G. G. 1964. Leaf temperatures of alpine plants in the field. - Planta 60: 497-505.

Sklenar, P. 2009. Presence of cushion plants increases community diversity in the high equatorial Andes. - Flora 204: 270-277.

Smith, V. R. 1987. The environment and biota of Marion Island. - South Afr. J. Sci. 83: 211-220. 
Smith, B. et al. 1995. A functional analysis of New Zealand alpine vegetation: variation in canopy roughness and functional diversity in response to an experimental wind barrier. - Funct. Ecol. 9: 904-912.
Walther, G.-R. et al. 2002. Ecological responses to recent climate change. - Nature 416: 389-395.

Zoller, H. etal. 2002. Pollination and breeding system of Eritrichium nanum (Boraginaceae). - Plant Syst. Evol. 233: 1-14. 